\title{
Simulation of photovoltaic (PV) power system performance of spacecraft in geostationary orbit using a prototype model
}

\author{
Muhammad Dokko Zubairu*, Ekundayo O. Ajala** \\ Department of Physics, Faculty of Science, University of Abuja* and **
}

\begin{abstract}
The most important system on-board any spacecraft is its electrical power system, as every other subsystem requires power to operate. Photovoltaic $(P V)$ array meets the total power requirements of the spacecraft in the geostationary orbit during its entire mission life. PV array consists of number of solar panel substrates on which solar cells are laid down in series and parallel for its power requirement generation. This paper presents the effects of varying temperature and irradiance on the solar energy generation based on the fundamental circuit equations of a solar PV cell model. Thus, an increase in irradiance at constant temperature, the voltage and current output also increase. Whereas, at constant irradiance, an increase in temperature decreases the power output from $P V$ array. The model produces various curves for $I-V$ and $P-V$ characteristics of the PV array.
\end{abstract}

Keywords: Spacecraft, Mission life, Photovoltaic array, Solar cell, Simulink

\section{Introduction}

The importance of photovoltaic (PV) cell, which is the building block of solar array, cannot be overemphasized. The photovoltaic cells are certainly convenient in comparison with other energy sources because the solar radiation it uses is the only external source of energy available in space. Any power system not using solar energy must carry its own source of energy onboard, such as the primary battery, fuel cell, and nuclear or chemical fuel. The cells convert sunlight into electrical energy to provide primary power for the Satellite. The cell designed for Geostationary spacecraft with a 15 -year mission life is to satisfy all electrical power requirements during sunlight portions of the orbit, including satellite housekeeping, payload operations, and battery charging. From the available design options, the spacecraft level optimization study is conducted to select the best combination of energy source, energy conversion, and energy storage technologies [Patel, 2005]. The primary criteria considered in this regard are usually low mass and low life cycle cost but largely influenced by the power level and the mission duration of the spacecraft [Patel, 2005]. The photovoltaic power system primarily consists of a solar array, a rechargeable battery, and a power regulator that regulates power flow between various components to control the bus voltage. Others include various sensors required to make the array and the battery work together. The number of each of these components needed depends on the spacecraft platform, mission, the duration in the orbit and the impact of the system's hardware on the Spacecraft design.

For the purpose of this paper where a prototype of geosynchronous Spacecraft is considered, Gallium Arsenide cells are used as power generator. These consist of a large number of cells arranged on a substrate, which convert solar energy into electric power. The cells are made in various shapes and sizes, which put out relatively required current and voltage. The first use of solar power in space dates back to march 17, 1958 when Vanguard 1 was launched utilizing six solar panels which provided less than one watt of power for over six years with $10 \%$ conversion efficiency [www.thirdwave.de/3w/tech/spacecraft/spacecraftpowergen.pdf, 2012]. Since then solar array technology has advanced considerably in the types of deployment, cell materials and efficiency improvement. Solar array deployment began with the drum-type spin stabilized vehicle where $40 \%$ of the array was exposed to the sun at any one time. Deployable paddle-like arrays evolved from the need for increased power outputs. With the technical evolution of thinner solar cells, a variety of rollout and foldout solar arrays have been designed and demonstrated. With the advent of flexible solar arrays, a much larger array area can be packaged for the same mass of a paddle-like deployable array. Solar cells are connected in series to maximize voltage and in parallel for high current.

The main contribution of this paper is to present the fundamental knowledge on the design and modeling of the blocks of PV modules based on Shockley model equation using Matlab/Simulink to demonstrate PV cells performance in geostationary orbit. This model is basically developed to simulate the behavior of a solar array and the objective is to design a tool, which can automatically update the values of solar cell parameters if there is any change in environmental conditions such as temperature and irradiance. 


\section{Photovoltaic Model}

Solar cell is basically a p-n junction fabricated in a thin layer of semi-conductor. Its simulation involves modeling of solar cells and taking into account the influence of illumination and temperatures along with representation of the network resulted from the panel's series - parallel cell assembly. Here we are dealing with Gallium Arsenide (GaAs) type of solar cells that is used mostly by geostationary spacecraft, e.g. NigComSat1R.The GaAs type is triple junction type (TJT) cells that has each sub-cell being reactive to different portion of solar spectrum to maximize utilization of the energies; the efficiency is about $19 \%$ but currently there are TJTs with efficiencies as much as $29 \%$ which far outweighs the existing double junction type (DJT) .It also has a higher energy band gap $\left(\mathrm{E}_{\mathrm{G}}=1.43-\mathrm{eV}\right)$. It is insensitive to wide temperature cycling, and has high radiation resistant. Solar cell models are commonly used for analysis of solar cell behavior. The most common approach to solar cell modeling is the use of a single diode solar cell equivalent circuit [Rauschenbach, 1980], shown in Figure 2.0. The current-voltage relation of a solar cell is described by:

$$
\mathrm{I}=I_{p h}-J_{g}\left[\mathrm{e}^{\left(\frac{\gamma+\left[K_{s} j\right.}{v_{\mathrm{t}}}\right)}-1\right]+\left(\frac{\gamma-I \mathrm{~N}_{s}}{n_{\mathrm{l}}}\right)
$$

Wher, $v_{t} 10$ un unuman vuraze.

$$
v_{*} \frac{\text { RET }}{8}
$$

The non-linearity and the implicit nature of the equation (1) require significant computational effort in the determination of its parameters. In many cases, the model includes only the variations of photocurrent $\left(I_{p h}\right)$ and diode saturation current $\left(\mathrm{I}_{\mathrm{s}}\right)$ while the values of other parameters are kept constant or adjusted for better curve fitting [Walker, 2000]. However, it is known that solar cell parameters are affected by temperature and irradiance, which further affects solar cell performance curves. Hence, for accurate modeling of a solar cell, it is essential to incorporate all of these effects. Various analytical methods have been proposed for the determination of junction parameters [Sharma et al, 1993] but applications of these methods are limited to the availability of test data and require significant computation. Progress has been reported in [Jervase et al, 2001], where a genetic algorithm has been implemented for solar cell parameter determination. This method requires an extensive set of I-V characteristic data as input.

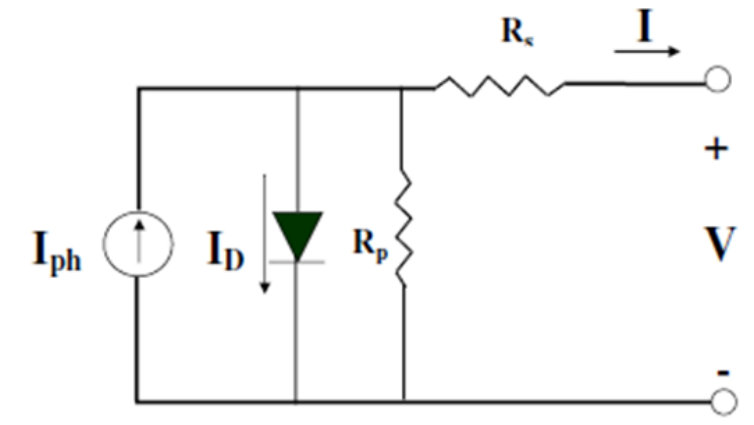

Figure 2.0; Solar Cell equivalent circuit [Rauschenbach, 1980]

\subsection{Photovoltaic Equivalent Circuit Model Equations}

The current model is based on a simplified single-diode model [Rauschenbach, 1980] to describe the electrical characteristics of solar cell. The behavior of the solar cell is determined from the cell characteristics given in the cell data sheet. The data to be used would be that of NigComsat-1R. An adapted version of this model is implemented using MATLAB/Simulink. The inputs to the model are:

- Illumination intensity

- Voltage across cell/array

- Operating temperature.

The simplified single-diode model ignores the effect of leakage currents eliminating the last term of Equation 1. In addition for multi-junction cells, where more than one diode is considered, the concept of a multijunction solar cell as a series connected diodes, can be used. These serially connected diodes are replaced by a single equivalent diode, using an additional factor $\Omega$, representing the number of junctions in solar cell; in this case $\Omega$ is equal to 1 . So Equation 1 can now be rewritten as:

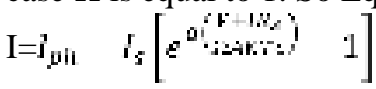


The current model needs the following four parameters; $V_{o c}$ (open circuit voltage), $I_{\mathrm{sc}}($ short circuit current), $\mathrm{I}_{\text {mpp }}$ (current at maximum power point) and $\mathrm{V}_{\text {mpp }}$ (voltage at maximum power point) along with their respective temperature coefficients which are represented by $\mathrm{dV}_{\mathrm{oc}}, \mathrm{dI}_{\mathrm{sc}}, \mathrm{dI}_{\mathrm{mpp}}$, and $\mathrm{dV}_{\mathrm{mpp}}$.

In these equations, $I_{p h}$ is the light generated current or photocurrent, $I_{s}$ is the cell saturated current, $q\left(1.6 \times 10^{-19} \mathrm{C}\right)$ is an electron charge, $\mathrm{k}\left(1.38 \times 10^{-23} \mathrm{~J} / \mathrm{K}\right)$ is a Boltzmann's constant, $\mathrm{T}_{\mathrm{c}}$ is the cell working temperature, $\mathrm{A}$ is an ideal factor, $R_{s}$ and $R_{p}$ is a series and shunt resistance respectively. The photocurrent mainly depends on the solar insolation current and varies with the cell temperature, which is described as:

$\mathrm{I}_{\mathrm{ph}}=|\operatorname{Isc}| \mathrm{d} I s c(T c \quad T o\} \mid \mathcal{G}$

Where $\mathrm{I}_{\mathrm{sc}}$ is the cell's short-circuit current at $25^{\circ} \mathrm{C}$ and $1 \mathrm{~kW} / \mathrm{m}^{2}, \mathrm{dI}_{\mathrm{sc}}$ is the cell's short-circuit temperature coefficient, $T_{0}$ is the cell's reference temperature, $T_{c}$ is the cell's working temperature, and $G$ is the solar insolation in $\mathrm{W} / \mathrm{m}^{2}$. On the other hand, the cell's saturation current varies with the cell temperature, which is described as:

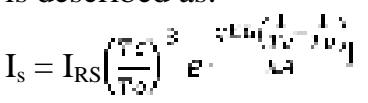

Where $I_{R S}$ is the cell's reverse saturation current at a reference temperature and a solar radiation $E_{G}$ is the band-gap energy of the semi-conductor used in the cell.

Furthermore, the $\mathrm{V}_{\mathrm{oc}}$ parameter is obtained by assuming the output current is zero. Given the PV open-circuit voltage $\mathrm{V}_{\mathrm{oc}}$ at reference temperature and ignoring the shunt-leakage current, the reverse saturation current at reference temperature can be approximately obtained as:

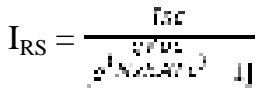

In addition, the maximum power can be expressed as:

$\mathrm{P}_{\max }=\mathrm{V}_{\max } \mathrm{I}_{\max }=\gamma \mathrm{V}_{\mathrm{oc}} \mathrm{I}_{\mathrm{sc}}$

where $\mathrm{V}_{\max }$ and $\mathrm{I}_{\max }$ are terminal voltage and output current of PV module at maximum power point (MPP), and $\gamma$ is the cell fill factor which is a measure of cell quality.

\section{Solar Array Simulink Model}

The spacecraft solar array system analysis model has been developed in Matlab/Simulink. The Matlab/Simulink schematic of this model for the standard solar array is shown in figure 3.0 (a). In this section, the models for a Prototype Solar Module are discussed.

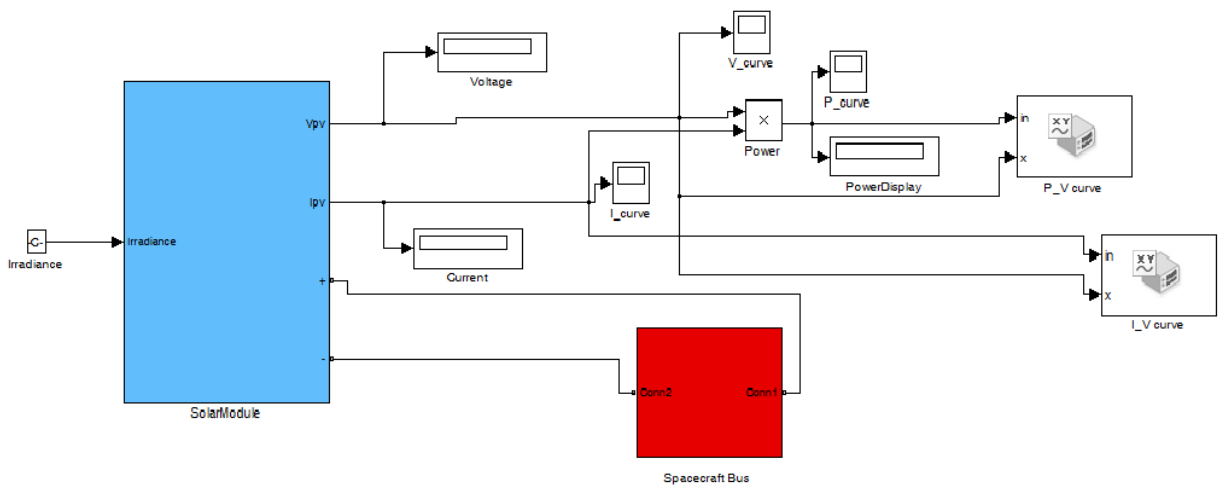

Figure 3.0 (A): Simulink Schematic Of A Prototype Solar Module

\subsection{Solar Module}

The purpose of this block is to simulate the behavior of the solar array over given simulation time. The inputs to the model are Irradiance and array configuration conditions. This is more elaborate in Figure 3.0 (b), which is the subset of Solar Module. The central entity of this block is the model of solar array, solar panel, sections and solar cells. 


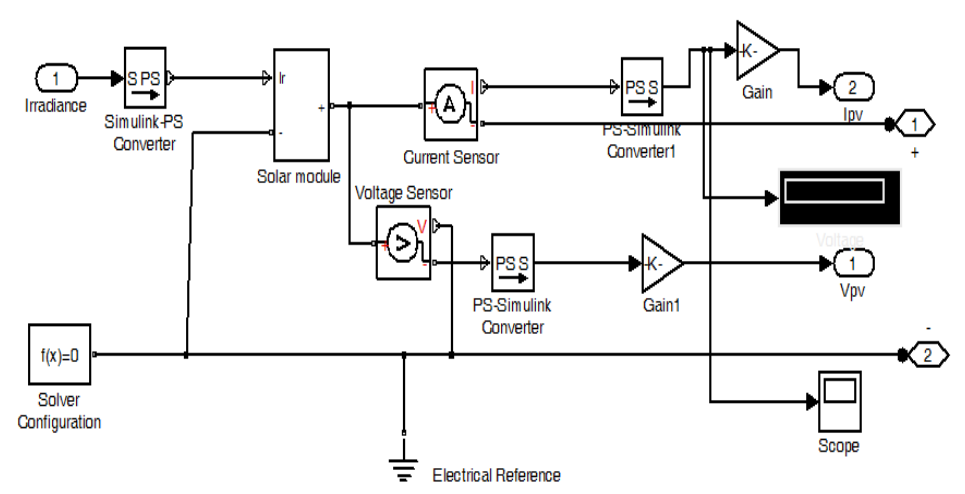

Figure 3.0 (b): Simulink schematic of Solar Module

The model shown in Figure 3.0 (b) gives the elaborate representation of the Solar Module blocks. The module takes in Irradiance in the form of physical signal as an input as well as Solver configuration to give out various signals in the form of Current and Voltage. The Simulink-PS Converters in the diagram converts the unitless Simulink input signal to a Physical Signal. The sensors give out its respective values.

Inside the Solar module are two solar arrays. These two solar arrays take irradiance as input and output through the two terminals; positive and negative. Also, inside these arrays are three solar panels per each solar array, making a total of six solar panels.

Thus, each solar panel has being distributed into sections where solar cells are furthermore connected in series formed by six solar cells of SimElectronics Library. These structures, in general can be built in any configurations by connecting multiple strings of solar cells in series or in parallels.

\section{Results \& Discussions}

In this model, the typical electrical parameters of solar cells used for its evaluation are given in [Cast, 2011]. These are $I_{s c}=0.39486 \mathrm{~A}, I_{m p}=0.3686 \mathrm{~A}, V_{m p}=0.86 \mathrm{~V}, V_{\mathrm{oc}}=1.010 \mathrm{~V}, \mathrm{FF}=0.79, \eta=19 \%, \mathrm{G}=$ $1000 \mathrm{~W} / \mathrm{m}^{2}, \mathrm{~T}_{0}=25^{0} \mathrm{C}$. Theseinput data used for the simulation were the ones given by the Tianjin Institute of Power Sources (TIPS) China. This cell type is qualified by Dong Fang Hong-4 (DFH-4) platform. The graphs at the figure 4.0 show the current, voltage and Power, which are obtained at output of photovoltaic array. These are the curves of current, voltage and power versus time. When the resistance varies, the current and voltage vary depending on the voltage-time relationship, which gives the power curve.

The I-V and P-V characteristics of the photovoltaic array are given in figure 4.1 and figure 4.2. The I-V and $\mathrm{P}-\mathrm{V}$ curves represent the standard behavior of the photovoltaic array. In the middle of this characteristic is the maximum power point. This point is critical for this kind of system for maximum power extraction from the photovoltaic array. The results show the main objective of trying to operate around this maximum point in order to make the photovoltaic cells work at maximum efficiency.

To illustrate the effects of Irradiance on photovoltaic cells, equation 4 calculates the PV cell photocurrent, which depends on the radiation and the temperature accordingly. Figure 4.3 and figure 4.4 show the effect of irradiance on the PV cell for both $\mathrm{I}-\mathrm{V}$ and P-V curves respectively. In the simulation, the temperature is kept constant at $25^{\circ} \mathrm{C}$ while the irradiance varies for $800 \mathrm{~W} / \mathrm{m}^{2}, 1000 \mathrm{~W} / \mathrm{m}^{2}, 1200 \mathrm{~W} / \mathrm{m}^{2}$ and $1400 \mathrm{~W} / \mathrm{m}^{2}$. Thus, it is observed that an increase in solar radiation at constant temperature the voltage and current output from PV array also increase. Hence, at higher insolation, required voltage is achieved as well as the power output.

For the temperature effects illustrations, the diode reverse saturation current as shown in equation 5 varies as a cubic function of the temperature. And for a given solar radiation, when the cell temperature increases at constant irradiance, the open circuit voltage $V_{o c}$ drops slightly, while the short circuit current $I_{s c}$ increases. The voltage drop can only have effect on the charge regulator if it falls below the required margin for the intended output and also if not operating within the mpp there will be drop but operating within the mpp there will be rise in power; it is a trade-off in performance balancing. In space scenario coverglass and other anti-glare are utilized to control the effect of degradations. This behavior is validated and presented in figures 4.5 and 4.6. 

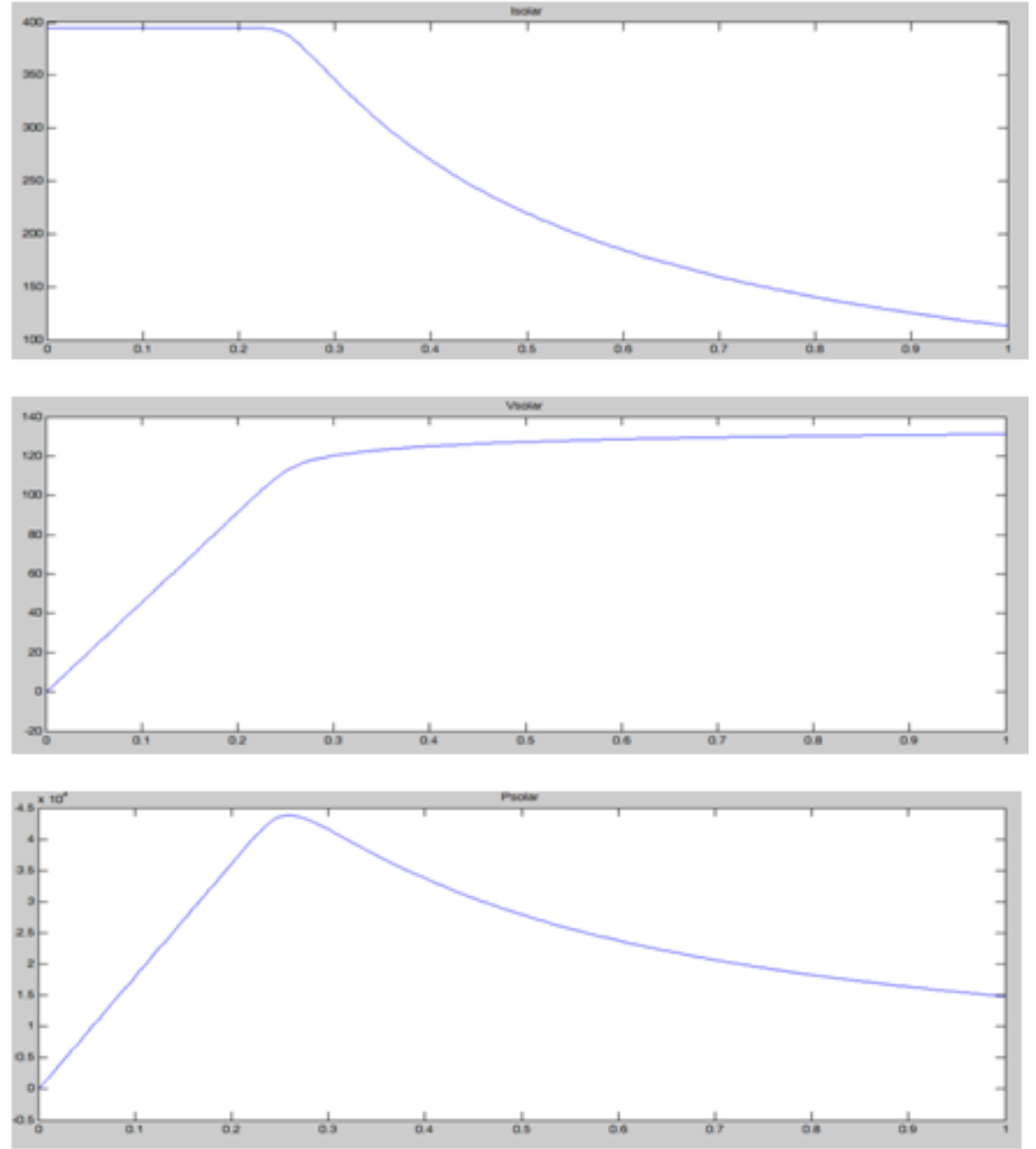

Figure 4.0: Current, Voltage and Power versus time curves for photovoltaic array

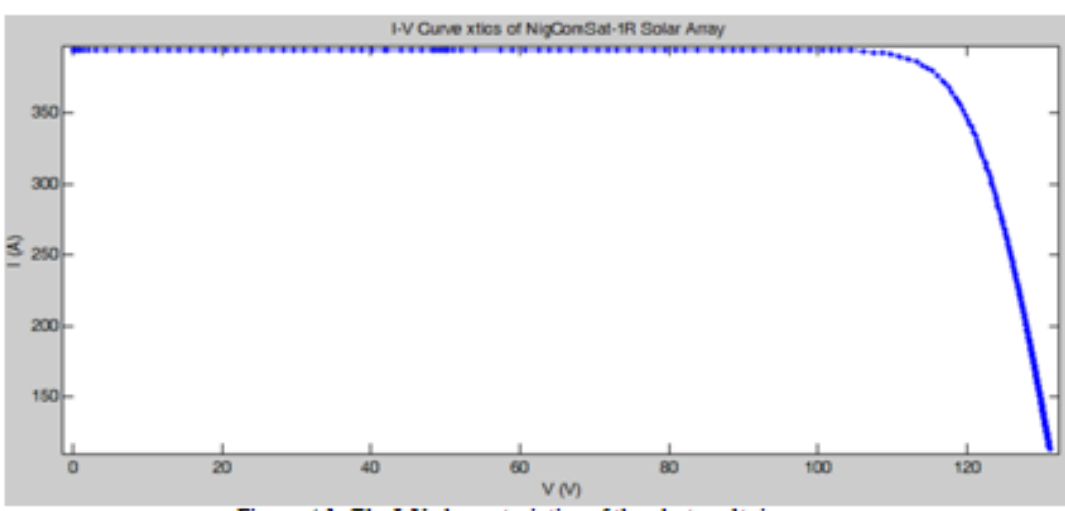

Figure 4.1: The I-V characteristics of the photovoltaic array

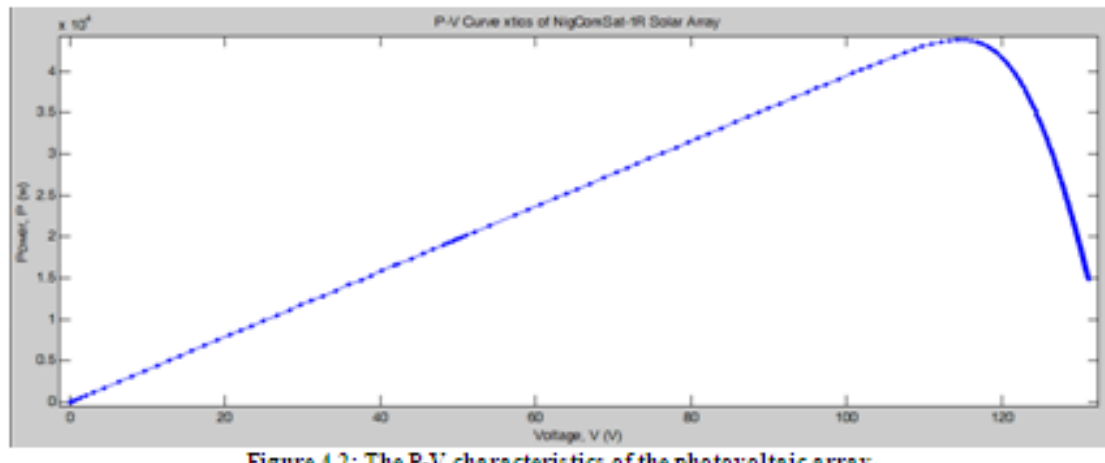

Figure 4.2: The P-V characteristics of the photovoltaic array 

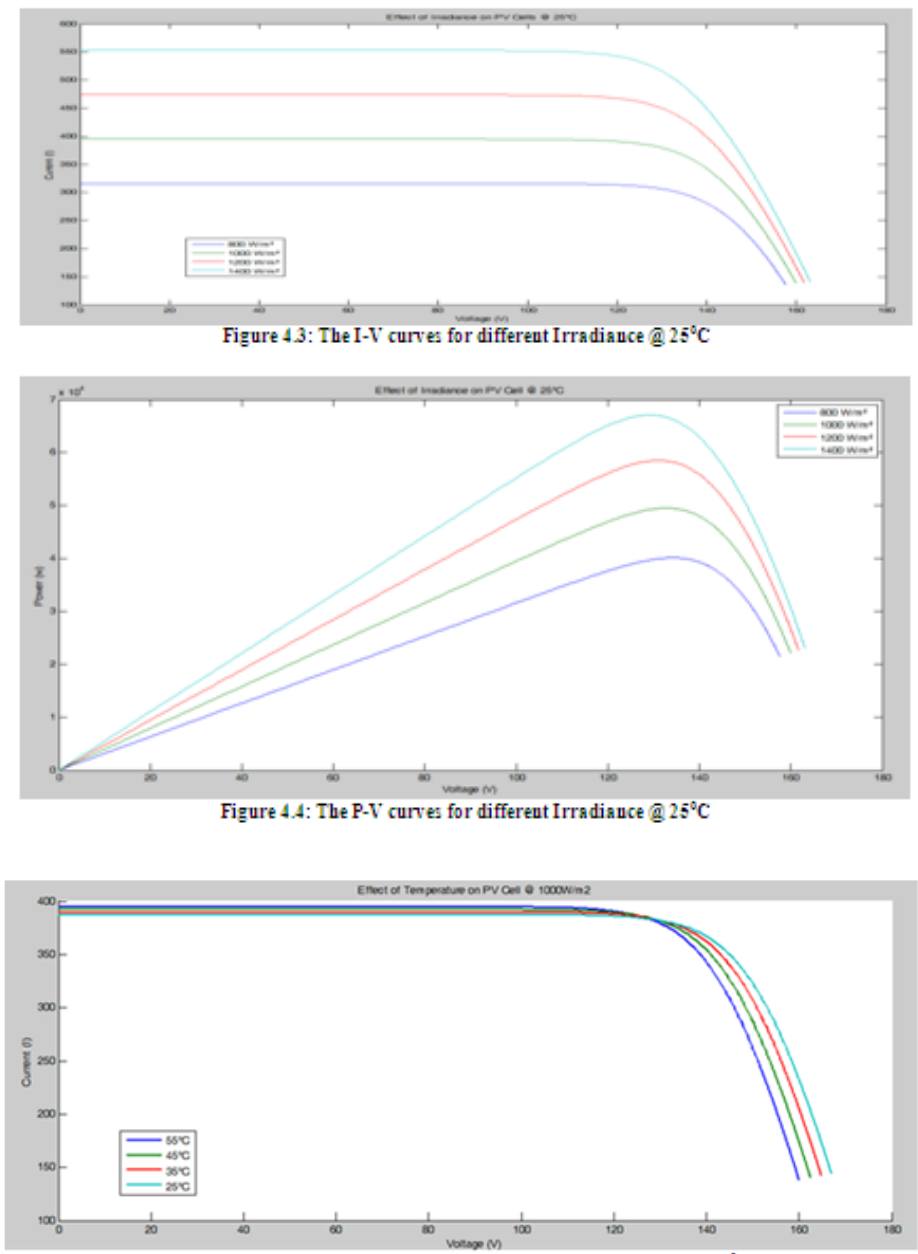

Figure 4.5: The I-V Curres For Different Temperature @ 1000w/M

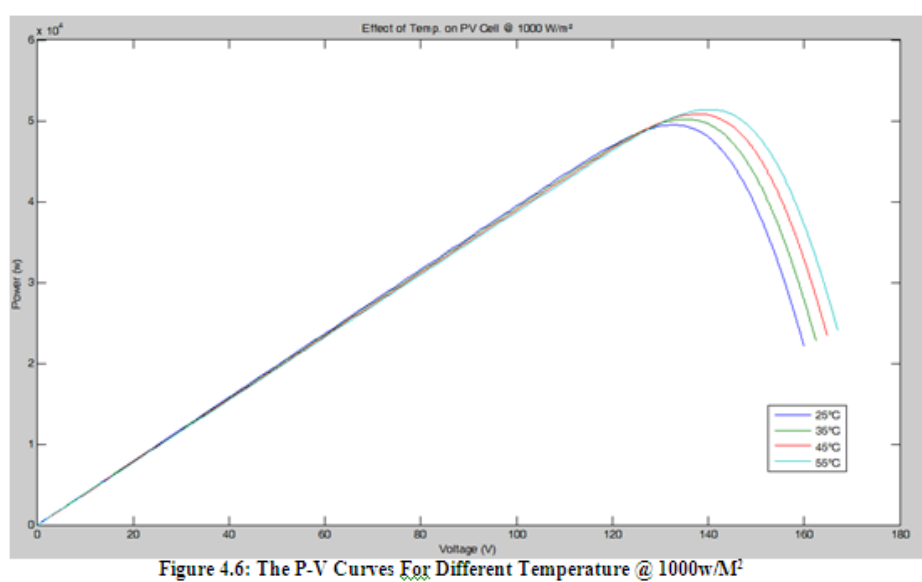

V. Conclusions

The various curves for I-V and P-V that were obtained from the simulation of the PV array in Simulink environment explains in detail its dependence on temperatures and irradiance level based on the fundamental circuit equations of a solar PV cell. The conversion system was designed in Matlab/Simulink environment. From the results of the study, one can benefit from this model as a photovoltaic generator in the framework of the Power system Matlab/Simulink toolbox. Hence, the model would provide a tool to predict the behavior of any solar PV cell, module and array under climatic and physical parameters changes. The model is useful for solar array sizing of generation unit in electrical power system of geostationary spacecraft and also applicable for current studies of spaced base power system (SPBS). 


\section{Acknowledgement}

I wish to heavily appreciate Prof. E.O. Ajala for his patience, ideas and advices, which are the base of this paper. Also, my acknowledgement goes to Engr. Adajah I.A, Mr. Ibrahim, D.I and Engr Ovurevu Suleiman whose approval for access to Nigcomsat_1r power system data helps a long way in formulating this model. I am especially thankful to Engr. Amalu I.N who was always there to solve my problems and guide me through any difficulties in the course of this work. Gratitude to Muhammad Alkali for his critical and intellectual contributions.

\section{Reference}

[1]. CAST, "Nigcomsat-1R Satellite Technical Data," S.C Centre, Ed., ed. Abuja 2011.

[2]. Jervase, J.A., Bourdoucen, H., and Al-Lawati, A., "Solar cell parameters extraction using genetic algorithm,' Journal of Measurement Science and Technology, Vol.12, 2001, pp.1922-1925.

[3]. Nelson J., "The Physics of Solar Cells," $11^{\text {st }}$ Edition, ed. Imperial College Press, 2005.

[4]. Patel M.R., "Spacecraft Power Systems," CRC Press, 2005.

[5]. Rauschenbusch H.S., "Solar Cell Array Design Handbook," JPL SP 43 - 38, vol.1, Van Nostrand Solar, 1980.

[6]. Sharma S.K., Pavithra D., Srinivasamurthy N. and Agrawal B.L., "Determination of Solar cell parameters: an analytical approach," Journal of Physics D: Applied Physics, Vol.26, No.7, 1993, pp.1130-1133.

[7]. Spacecraft Power Generation course, “www.thirdwave.de/3w/tech/spacecraft/spacecraft.powergen.pdf”, 15:20, $8^{\text {th }}$ November 2012

[8]. Walker, G., "Evaluating MPPT Converter Topologies Using a MATLAB PV model," Journal of Electrical and Electronics Engineering, Australia, Vol. 21, 2000, pp.49-56. 